\title{
GREEN SYNTHESIS OF SULPHUR NANOPARTICLES USING AQUEOUS GARLIC EXTRACT (Allium sativum)
}

\author{
K. Khairan ${ }^{1,2 *}$, Zahraturriaz ${ }^{1}$ and Z. Jalil ${ }^{2}$ \\ ${ }^{1}$ Department of Pharmacy, Syiah Kuala University, Banda Aceh, Indonesia, 23111. \\ ${ }^{2}$ Department of Physics, Syiah Kuala University, Banda Aceh, Indonesia, 23111 \\ *E-mail: khairankhairan@unsyiah.ac.id
}

\begin{abstract}
Sulphur nanoparticles have been successfully prepared from sodium thiosulphate pentahydrate $\left(\mathrm{Na}_{2} \mathrm{~S}_{2} \mathrm{O}_{3} \cdot 5 \mathrm{H}_{2} \mathrm{O}\right)$ in the presence and absence of aqueous garlic extract (Allium sativum). The resulting sulphur nanoparticles were examined by Fourier Transforms Infrared Spectroscopy (FT-IR), X-ray Diffraction (XRD), and Scanning Electron Microscopy (SEM). The average size of sulphur nanoparticles was determined by XRD analysis and calculated using the DebyeScherrer formula. The results showed that the size of sulphur nanoparticles synthesized in the presence and absence of aqueous garlic extract were 55.613 and $70.908 \mathrm{~nm}$ respectively. The SEM analysis showed that sulphur nanoparticles synthesized in the presence of aqueous garlic extract were clear and lighter with smooth spherical shapes. The antifungal activities of the sulphur nanoparticles were determined by a disc diffusion method, and the results showed that sulphur nanoparticles synthesized in the presence and absence of aqueous garlic extract (Allium sativum) have no effect on clinical isolate of Candida albicans at concentrations of 200, 400, and $600 \mathrm{ppm}$.
\end{abstract}

Keywords: Sulphur nanoparticles, Allium sativum, sodium thiosulphate pentahydrate, Candida albicans

(C) RASĀYAN. All rights reserved

\section{INTRODUCTION}

Much attention has been paid to nanotechnology since it can be applied many different areas in different scientific fields, such as green energy ${ }^{1}$, catalysis, agriculture, composites, antimicrobial agents, industrial applications, and medicines. Nanoparticles can be synthesized using many different methods, such as electrochemical, micro-emulsion, cell membrane, sublimation, sedimentation, liquid phase chemical precipitation methods ${ }^{2,3,4}$. However, all these methods are expensive and hard to scale-up, in addition to needing a lot of surfactants, and being environmentally unfriendly. During the past decade, many efforts towards the synthesis of nanoparticles have been made. Environmentally friendly synthesis or green synthesis is one of the best methods for the application of synthesis of nanoparticles. This method was chosen because it is easy, simple, and convenient, as well as because it, requires less reaction time, and is also not harmful to the environment ${ }^{5}$.

Green synthesis is a method of using plant extracts for the biosynthesis of nanoparticles. This method is widely used by researchers because it is considered easy, cheap and environmentally friendly ${ }^{5}$. It has been reported that many bio-materials including plants can be used as bioreactors for the synthesis of nanoparticles. As bioreactors, plants are able to transform inorganic metal ions (metal bioaccumulation) into metal nanoparticles through the reductive capacities of the metabolites (such as terpenoids, alkaloids, polyphenols, tannins, and steroids) present in the plants ${ }^{6}$. For example, Brassica juncea and Medicago sativa was shown to accumulate $50 \mathrm{~nm}$ of silver nanoparticles when silver nitrate was used as a substrate ${ }^{7}$, Iris pseudacorus accumulated copper nanoparticles of $2 \mathrm{~nm}$ with substrates containing salts ${ }^{8}$, Pleurotuscornucopiae var. citrinopileatus accumulated silver nanoparticles with the size of $100 \mathrm{~nm}^{9}$, Xanthium strumarium or Xanthium indicum Kone accumulated gold nanoparticles with sizes ranging from $9.60 \mathrm{~nm}$ to $11.70 \mathrm{~nm}^{10}$ and Allium cepa accumulated gold nanoparticles of $45.42 \mathrm{~nm}^{11}$.

Rasayan J. Chem., 12(1), 50-57(2019)

http://dx.doi.org/10.31788/RJC.2019.1214073

CrossMark 
In this study, we examined the synthesis of sulphur nanoparticles. Sulphur nanoparticles are non-metal and are also a safe element. As a safe element, sulphur has the ability to form organosulfur compounds in cells ${ }^{12}$. Thus, sulphur nanoparticles have received increased attention from researchers. Nida ${ }^{13}$ have synthesized sulphur nanoparticles using Melia azedarach leaf extract and the results showed that the extract accumulated sulphur nanoparticles with a size of $20 \mathrm{~nm}$. Nida ${ }^{5}$ also showed that aqueous Punica granatum peels extract accumulated sulphur nanoparticles of $50 \mathrm{~nm}$. In this study, we employed the herb-garlic (Allium sativum) specifically aqueous garlic extract for the synthesis of sulphur nanoparticles. Garlic has been known to contain organosulphur compounds that can act potentially as reducing agents. Garlic has been known to contain lipid and water-soluble compounds. The lipid soluble compounds from garlic include diallyl sulphide (DAS), diallyl disulphide (DADS), and diallyl trisulphide (DATS). The watersoluble compounds include $S$-allyl cystein (SAC), and $S$-allyl mercaptocysteine (SAMC) ${ }^{14}$.

The main aim of this study is to synthesize sulphur nanoparticles using an environmentally friendly, green method with aqueous garlic extract (Allium sativum) and to examine the nanoparticles using FT-IR, XRD, and SEM analysis. The other aim of this study is to investigate the activity of sulphur nanoparticles on clinical isolate of Candida albicans.

Material and Methods

\section{EXPERIMENTAL}

Sodium thiosulphate pentahydrate $\left(\mathrm{Na}_{2} \mathrm{~S}_{2} \mathrm{O}_{3} .5 \mathrm{H}_{2} \mathrm{O}\right)$, was purchased from Sigma Aldrich. Hydrochloric acid ( $\mathrm{HCl}) 10 \%$, ethanol absolute, and $\mathrm{NaCl}$. Allium sativum were obtained from a traditional market, Ulee Kareng, Banda Aceh, Indonesia.

\section{Preparation of Aqueous Extract of Allium sativum}

$50 \mathrm{~g}$ of fresh garlic was mixed with $500 \mathrm{ml}$ aquadest and boiled for 20 minutes. The mixtures of garlic were then cooled to room temperature, then filtered using Whatman Paper No. 1 for the purpose of removing raw materials from the extract. The aqueous garlic extract was then centrifuged for 5 minutes at $1200 \mathrm{rpm}$ for the purpose of removing heavy biomaterials. The filtrate obtained was stored in a refrigerator for further purposes.

\section{Phytochemicals Screening of Garlic Extract}

The methods described by Harborne ${ }^{14}$ were used for the phytochemicals tests. The phytochemicals tests of aqueous garlic extract in this study included alkaloids, flavonoids, saponins, and tannins.

\section{Synthesis of Sulphur Nanoparticles \\ General Procedure for Synthesis of Sulphur Nanoparticles}

Nanoparticles of sulphur were synthesized according to the method developed by $\mathrm{Nida}^{3}$, with slight modifications. Briefly, $49.6 \mathrm{~g}$ of sodium thiosulfate pentahydrate $\left(\mathrm{Na}_{2} \mathrm{~S}_{2} \mathrm{O}_{3} \cdot 5 \mathrm{H}_{2} \mathrm{O}\right)$ was dissolved in the presence and, separately in the absence of $500 \mathrm{ml}$ of garlic extract with mild stirring at room temperature for 10 minutes. Then, the mixtures were diluted with $500 \mathrm{ml}$ of aquadest. Subsequently, $10 \%$ hydrochloric acid was added drop by drop using a dropping funnel while being stirred. The stirring, was kept constant to allow the sulphur to precipitate uniformly. The solid sulphur (in the presence and absence of $500 \mathrm{ml}$ of garlic extract) particles obtained were then centrifuged for 10 minutes at $5000 \mathrm{rpm}$ at air temperature. The supernatant was removed and the sulphur precipitate was washed with aquadest repeatedly, and afterward washed with absolute ethanol in order to remove impurities or biological materials from the products. Eventually, the products (in the presence and absence of aqueous garlic extract) were freeze-dried and stored at room temperature for the next analysis. The disproportionation reaction between sodium thiosulphate pentahydrate and hydrochloric acid is presented below:

$$
\mathrm{Na}_{2} \mathrm{~S}_{2} \mathrm{O}_{3} \cdot 5 \mathrm{H}_{2} \mathrm{O}_{(\mathrm{s})}+2 \mathrm{HCl}_{(\mathrm{aq})} \rightarrow 2 \mathrm{NaCl}_{(\mathrm{aq})}+\mathrm{S}(\mathrm{s})+\mathrm{SO}_{2(\mathrm{aq})}+6 \mathrm{H}_{2} \mathrm{O}_{(\mathrm{l})}
$$

\section{Characterization of Sulphur Nanoparticles \\ Fourier Transform Infrared (FT-IR) Analysis}

FT-IR spectroscopy (using an Agilent Technologies Cary 630 model) was used to determine the Fourier Transmission Infrared (FT-IR) spectra for aqueous garlic extract, sodium thiosulfate pentahydrate, and 
RASĀYAN $J$. Chem.

Vol. 12 | No. 1 |50 - 57| January - March | 2019

sulphur nanoparticles synthesized in the presence and absence of aqueous garlic extract. The FT-IR spectra were recorded in the rage of $4000-650 \mathrm{~cm}^{-1}$.

\section{X-ray Diffraction (X-RD) Analysis of Synthesized Sulphur Nanoparticles}

The average size of crystalline sulphur nanoparticles that were synthesized in the presence and absence of aqueous garlic extract were determined by X-ray Diffraction, (X-RD) (using a Shimadzu D6000 model) and calculated using the Debye-Scherrer formula. The $\mathrm{X}-\mathrm{RD}$ was equipped with $\mathrm{Cu} \mathrm{K} \alpha$ radiation sources using the $\mathrm{Ni}$ as a filter. The instrument was set at $40 \mathrm{kV} / 30 \mathrm{~mA}$, with $\lambda$ in 1,54060 $\mathrm{A}$. All X-RD data were conjoined under the same experimental condition, with an angular range of $20^{\circ} \leq 2 \theta \leq 60^{\circ}$. The enumeration method was done gradually with a data distance of $0.02^{\circ}$.

\section{Scanning Electron Microscopy (SEM) Analysis of Synthesized Sulphur Nanoparticles}

The Scanning Electron Microscopy (SEM) analysis of the synthesized sulphur nanoparticles was done using a Quanta SEI 450 SEM machine at $15 \mathrm{kV}$, with the magnifications at 5.000 and 10.000x.

\section{Antifungal Activity}

The antifungal activity of synthesized sulphur nanoparticles was done by a disc diffusion (Kirby-Bauer) method. Sabouraud's Dextrose Agar (SDA) was poured into sterile petri dishes and allowed to solidify, and clinical cultures of Candida albicans was spread all over the surface of the solidified SDA using a cotton bud. The paper disc with a diameter of approximately $6 \mathrm{~mm}$ was placed on the surface of the agar medium. Each disc was filled with $10 \mu \mathrm{l}$ of sulphur nanoparticle solutions with the concentrations of 200,400 , and $600 \mathrm{ppm}$. Initially, sulphur nanoparticles were vortexed for 5 minutes, then sonicated for 15 minutes at room temperature to dissolve the sulphur nanoparticles. In this assay, a paper disc of nystatin was used as a positive control and the aqueous garlic extract as a comparison. The plates were incubated at $37^{\circ} \mathrm{C}$ for 48 hours, and the diameter of inhibition zones surrounding the agar disc was measured in millimeter using a ruler.

\section{Phytochemicals Screening of Aqueous Garlic Extract \\ RESULTS AND DISCUSSION}

The phytochemicals screening of aqueous garlic extract obtained is presented in Table-1. The table shows the results of the preliminary phytochemical screening. The results show that alkaloids and saponin were present in the extract, while flavonoids and tannins were absent.

Table-1: Phytochemicals profile of aqueous garlic extract (Allium sativum).

\begin{tabular}{c|c}
\hline Phytochemical constituent & Aqueous garlic extract \\
\hline Alkaloids & - \\
\hline Flavonoids & + \\
\hline Saponin & - \\
\hline Tannins &
\end{tabular}

note: $(+)=$ Present; $(-)=$ Absent

\section{Green Synthesis of Sulphur Nanoparticles}

The mechanisms of sulphur nanoparticles formation are presented in Fig.-1. The figure shows that the sulphur ions bind to garlic metabolites and stabilizing agents, then reduce to sulphur atoms into complex forms between sulphur atoms and metabolites, which form small sulphur atom nanoparticles through a coarsening process (nucleation process). This process continued until the sulphur particles assumed a stable shape and size.

The yields of the synthesized sulphur nanoparticles are presented in the Table- 2 . The table showed that the yield percentages of sulphur nanoparticles synthesized using aqueous garlic extract were smaller than the sulphur nanoparticles yield percentages synthesized in the absence of aqueous garlic extract. These results suggest that garlic metabolites can reduce the sulphur atoms to sulphur nanoparticles through a nucleation process. 


\section{FT-IR Analysis of Aqueous Garlic Extract and Sulphur Nanoparticles}

FT-IR analysis was performed in order to identify the potential of garlic extract as a bioreactor in the reduction of sulfur ions and the synthesis of sulphur nanoparticles. FT-IR analysis was conducted on a control (aqueous garlic extract), starting material (sodium thiosulphate pentahydrate, $\mathrm{Na}_{2} \mathrm{~S}_{2} \mathrm{O}_{3} \cdot 5 \mathrm{H}_{2} \mathrm{O}$ ), and the sulphur nanoparticle in the presence and absence of aqueous garlic extract. The FT-IR spectrum was recorded in the rage of $4000-650 \mathrm{~cm}^{-1}$.

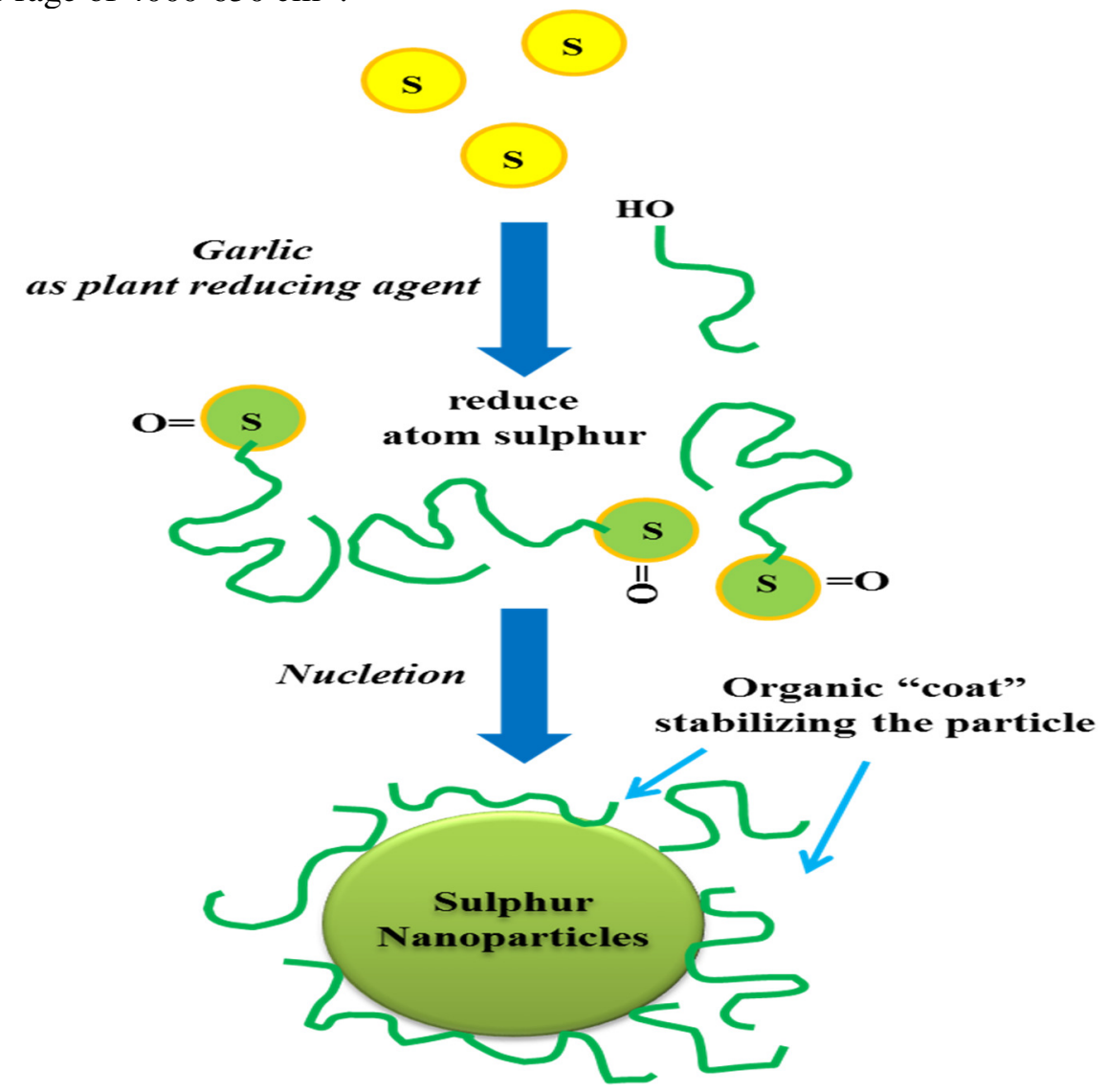

Fig.-1: A Schematic representation of sulphur nanoparticles synthesis in garlic extract ${ }^{6}$.

Table-2: The percentages yields of the sulphur nanoparticles synthesized in the presence and absence of garlic

\begin{tabular}{c|c|c|c}
\hline Methode of Synthesis & $\begin{array}{c}\mathrm{Na}_{2} \mathrm{~S}_{2} \mathrm{O}_{3} .5 \mathrm{H}_{2} \mathrm{O} \\
\text { (gram) }\end{array}$ & $\begin{array}{c}\text { Sulphur nanoparticle } \\
\text { (gram) }\end{array}$ & Percentage of yield (\%) \\
\hline In the presence of garlic extract & 24.80 & 1.71 & 6.80 \\
\hline In the absence of garlic extract & 24.80 & 1.99 & 8.00 \\
\hline
\end{tabular}

The FT-IR spectrum for aqueous garlic extract showed peaks at $3255.91 ; 2099.13 ; 1635.21 ; 1369.17$ and $1021.72 \mathrm{~cm}^{-1}$ (Fig.-2a). The FT-IR spectra peaks at $3255.91 \mathrm{~cm}^{-1}$ are represented the O-H stretching vibration, the presence of carbohydrate and amino acids. The spectra at $1635.21 \mathrm{~cm}^{-1}$ peaks represent the Amide I: $\mathrm{C}=\mathrm{O}$ stretching mainly: proteins and the spectra peaks at $1369.17 \mathrm{~cm}^{-1}$ is represents the $\mathrm{C}=\mathrm{S}$ stretching mainly: sulfur compounds. While, the spectra peaks at $1021.72 \mathrm{~cm}-1$ is represented the C-N stretching mainly: amino acids. The FT-IR spectra for sodium thiosulphate pentahydrate at approximately $3393.76 \mathrm{~cm}^{-1}$ caused by $\mathrm{O}-\mathrm{H}$ stretching vibration. The spectrum peaks at $1653.24,1156.21,1108.64$, and $992.66 \mathrm{~cm}^{-1}$ are characteristic peaks of sodium thiosulphate pentahydrate (Fig.-2b). However, the FT-IR spectrum of freeze-dried sulphur nanoparticles in the presence of aqueous garlic extract showed characteristic peaks at $3809.37,2263.92,2072.71,1626.73$, and $1511.54 \mathrm{~cm}^{-1}$, which corresponds to different biomolecules that are responsible for stabilizing and dispersing sulphur nanoparticles synthesized during the process of synthesis (Fig.-2c). Meanwhile, the FT-IR spectrum of freeze-dried sulphur 
RASĀYAN $J$. Chem.

Vol. 12 | No. 1 |50 - 57| January - March | 2019

nanoparticles synthesized in the absence of aqueous garlic extract showed at $3757.12 \mathrm{~cm}-1$ which is probably C-H stretching vibration. Furthermore, the spectra's traits at $1116.68 \mathrm{~cm}^{-1}$ can be assigned to thiocarbonyl groups $(\mathrm{S}=0)$ of the precursor (Fig.-2d). The overtones were appeared in the region spectrum ranges from $2300-2000 \mathrm{~cm}^{-1}$ at all samples and usually fairly weak.

\section{XRD Analysis of Synthesized Sulphur Nanoparticles}

The X-ray Diffraction (XRD) analysis of synthesized sulphur nanoparticles is presented in Table 3. The data in the table below indicates that the synthesized sulphur nanoparticles were crystalized. The diffraction peaks of the sulphur are well-matched with the standard monoclinic phase sulphur diffraction pattern, according to the JCPDS (Joint Committee for Powder Diffraction Standard).
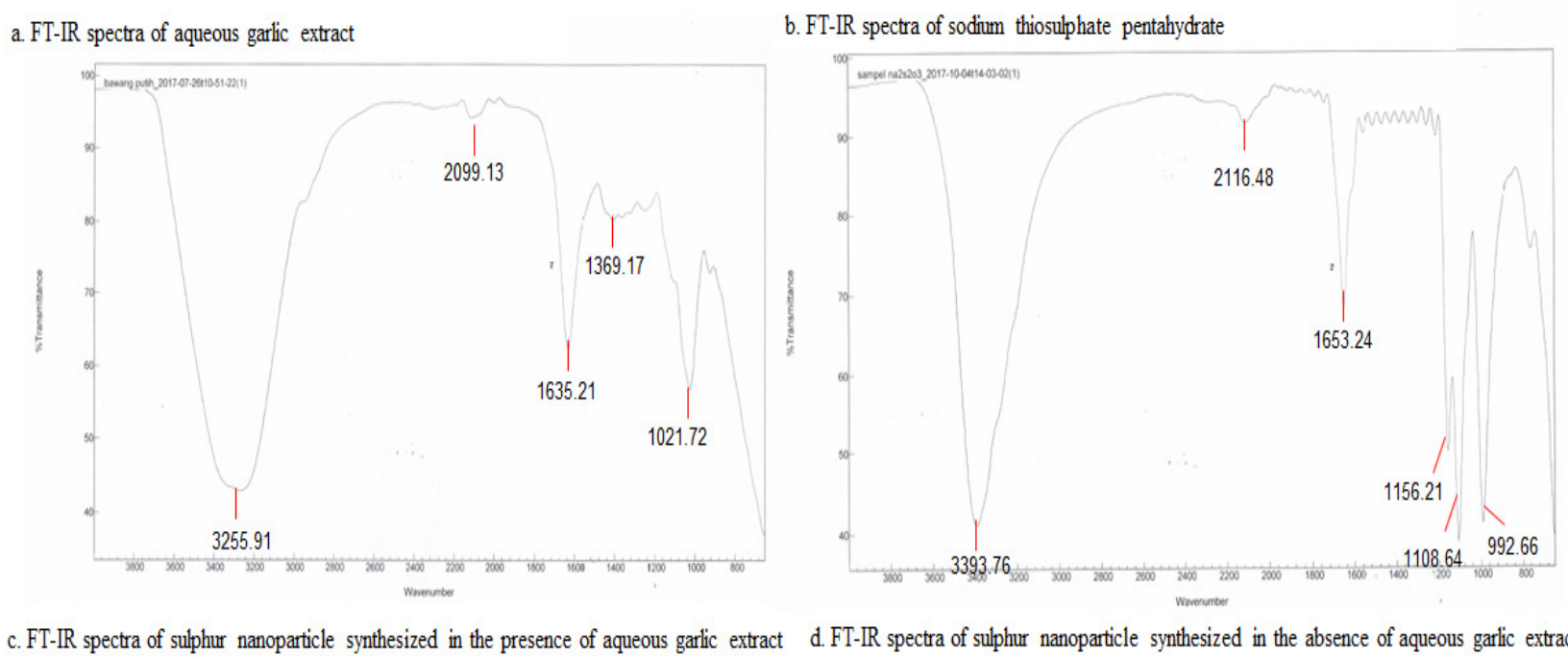

c. FT-IR spectra of sulphur nanoparticle synthesized in the presence of aqueous garlic extract
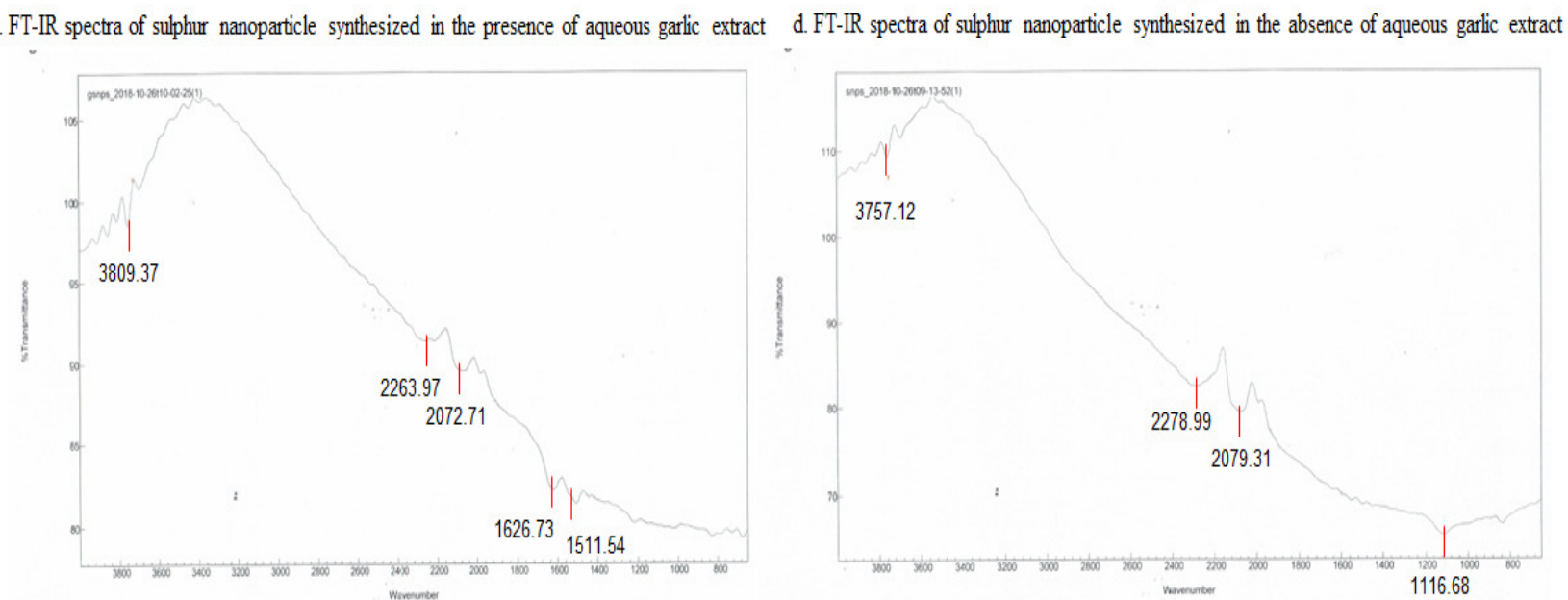

Fig.-2: The IR spectra of aqueous garlic extracts (a), sodium thiosulphate pentahydrate (b), freeze-dried synthesized sulphur nanoparticles in the presence of aqueous garlic extract (c), and freeze-dried synthesized sulphur nanoparticles in the absence of garlic extract $(d)$.

The average size of the sulphur nanoparticles synthesized was calculated using the Debye-Scherrer formula as shown below:

$$
\mathrm{D}=\mathrm{K} . \lambda / \beta \cos \theta
$$

Where $\mathrm{D}$ is the mean diameter of nanoparticles, $\mathrm{K}$ is the Scherrer constant with a value from 0.9 to $1, \lambda$ is the wavelength of the X-ray radiation source $(0.12030-0.15340 \mathrm{~mm}), \beta$ is the full width at the halfmaximum value of XRD diffraction, and $\theta$ is the half diffraction angle or Bragg angle.

The patterns of XRD are thought to be crystalline and amorphous (Fig.-3). The size of sulphur nanoparticle crystals synthesized using aqueous garlic extract $55.61 \mathrm{~nm}$, and the crystal size of sulfur nanoparticle 
synthesized in the absence of aqueous garlic extract was $70.90 \mathrm{~nm}$. The XRD analysis revealed that the diffraction peak range of $10-80^{\circ}$ and $2 \theta$ diffraction of sulphur nanoparticles (in the presence and absence of garlic) matched well with the database at $20.882^{\circ}$ and $20.823^{\circ}$ respectively (Table-3).

\section{SEM Analysis of Synthesized Sulphur Nanoparticles}

In the SEM analysis, the suspended sulphur nanoparticles in strerile aquadest were examined with Scanning Electron Microscopy (SEM), using a Quanta SEI 450 SEM machine at $15 \mathrm{kV}$ with a magnification of 5.000 and 10.000x. SEM images of the sulphur nanoparticles synthesized in the presence and absence of aqueous garlic extract are displayed in Fig.-4.

The results of the calculation from the Scherrer equation, as shown in Table-3, indicate that the sulphur nanoparticles synthesized in the presence of garlic extract are smaller than the sulphur nanoparticle synthesized without garlic extract. Fig. 4a indicated that, in the presence of aqueous garlic extract, the distribution of the particles size was more uniform, and the particles tended to be clearer, lighter and more able to prevent the tendency to agglomerate, compared to the sulphur nanoparticles prepared in the absence of aqueous garlic extract (Fig.-4b). These facts show that garlic extract was involved in reduction and as a stabilizing agent for sulphur nanoparticles during the synthesis process. This suggests that garlic extract plays a major role in the decreasing the particles size (Table-3), and is effective in controlling the size of sulphur nanoparticles ${ }^{16}$.
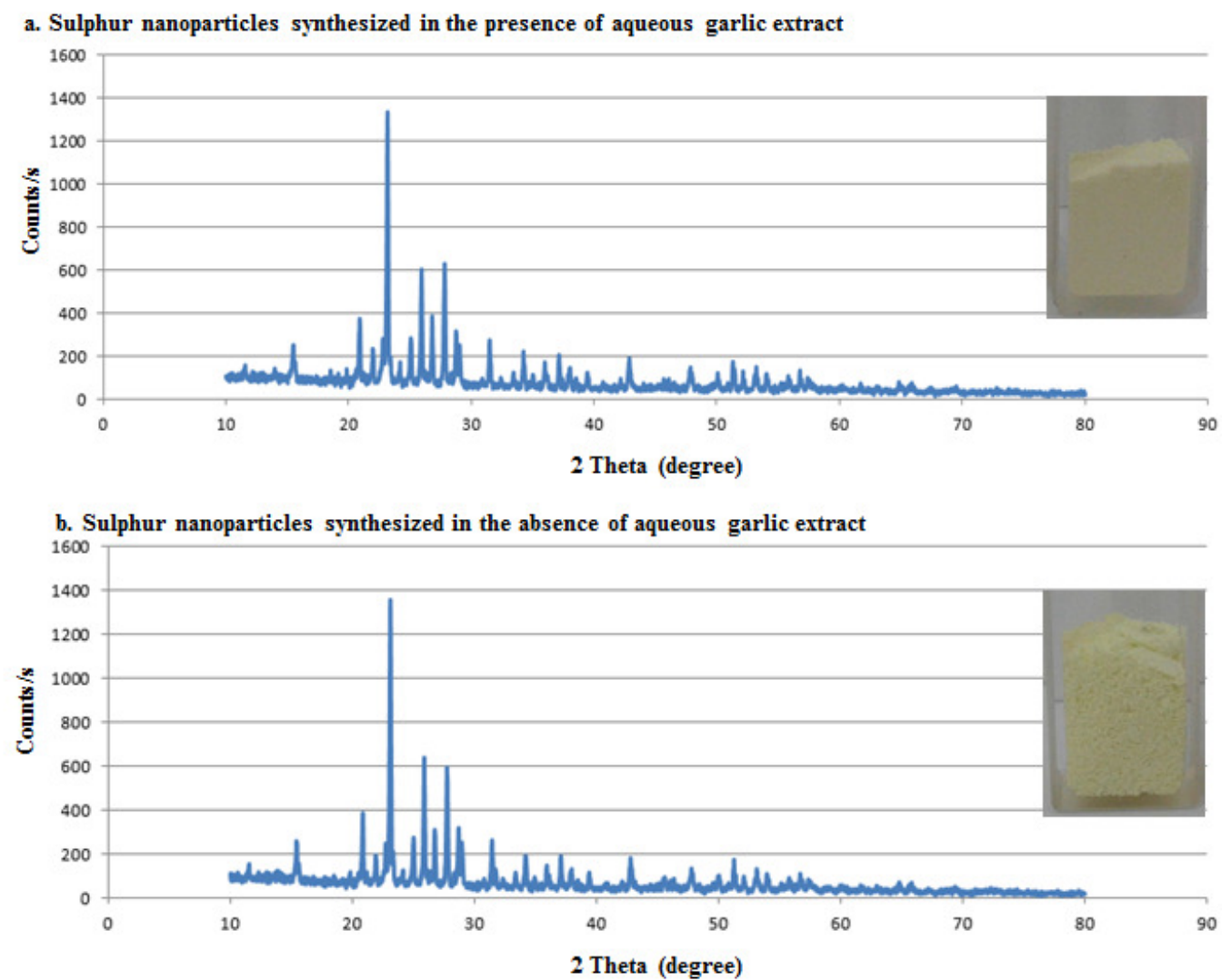

Fig.-3: X-RD analysis of sulphur nanoparticles synthesized in the presence and absence of aqueous garlic extract.

\section{The activity of Sulphur Nanoparticles Synthesized on Clinical Isolate Candida albicans}

The activity of the sulphur nanoparticles synthesized on clinical isolate of Candida albicans is presented in Fig.-5. The results show that the sulphur nanoparticles synthesized in the presence and absence of aqueous garlic extract showed no inhibition effect on clinical isolate of Candida albicans after exposure for 24h at concentrations of 200,400 and $600 \mathrm{ppm}$ by a disc diffusion method $(10 \mu \mathrm{l} / \mathrm{disc})$. Nystatin $(10 \mu \mathrm{l} / \mathrm{disc})$ was

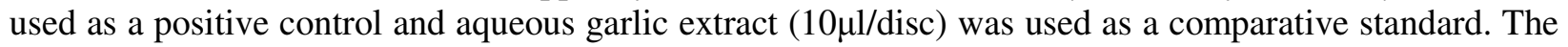


RASĀYAN J. Chem.

Vol. 12 | No. 1 |50 - 57| January - March | 2019

results showed that nystatin and aqueous garlic extract have a strong inhibitory effect on the clinical isolate of Candida albicans.

Table-3: XRD analysis sulphur nanoparticles synthesized in the presence and absence of garlic extract

\begin{tabular}{|c|c|c|c|c|c|c|c|}
\hline \multirow[t]{2}{*}{ Method of synthesis } & \multicolumn{2}{|c|}{$2 \theta\left(^{\circ}\right)$} & \multirow{2}{*}{$\begin{array}{c}\text { FWHM } \\
\left({ }^{\circ}\right)\end{array}$} & \multirow{2}{*}{$\begin{array}{l}\text { Intensity } \\
(\%)\end{array}$} & \multirow[t]{2}{*}{ Phase } & \multirow{2}{*}{$\begin{array}{c}\theta \\
\left(^{\circ}\right)\end{array}$} & \multirow{2}{*}{$\begin{array}{l}\text { Size } \\
(\mathrm{nm})\end{array}$} \\
\hline & Sample & Database & & & & & \\
\hline $\begin{array}{c}\text { In the presence of } \\
\text { aqueous garlic extract }\end{array}$ & 20.882 & 20.963 & 0.153 & 22 & $\begin{array}{l}\text { sulphur } \\
\text { (S) }\end{array}$ & 10.441 & $\begin{array}{c}55.6 \\
13\end{array}$ \\
\hline $\begin{array}{c}\text { In the absence of } \\
\text { aqueous garlic extract }\end{array}$ & 20.823 & 20.963 & 0.120 & 24 & $\begin{array}{l}\text { sulphur } \\
(\mathrm{S})\end{array}$ & 10.411 & $\begin{array}{c}70.9 \\
08\end{array}$ \\
\hline
\end{tabular}

a JCPDS (Joint Committee for Powder DiffractionSstandard)

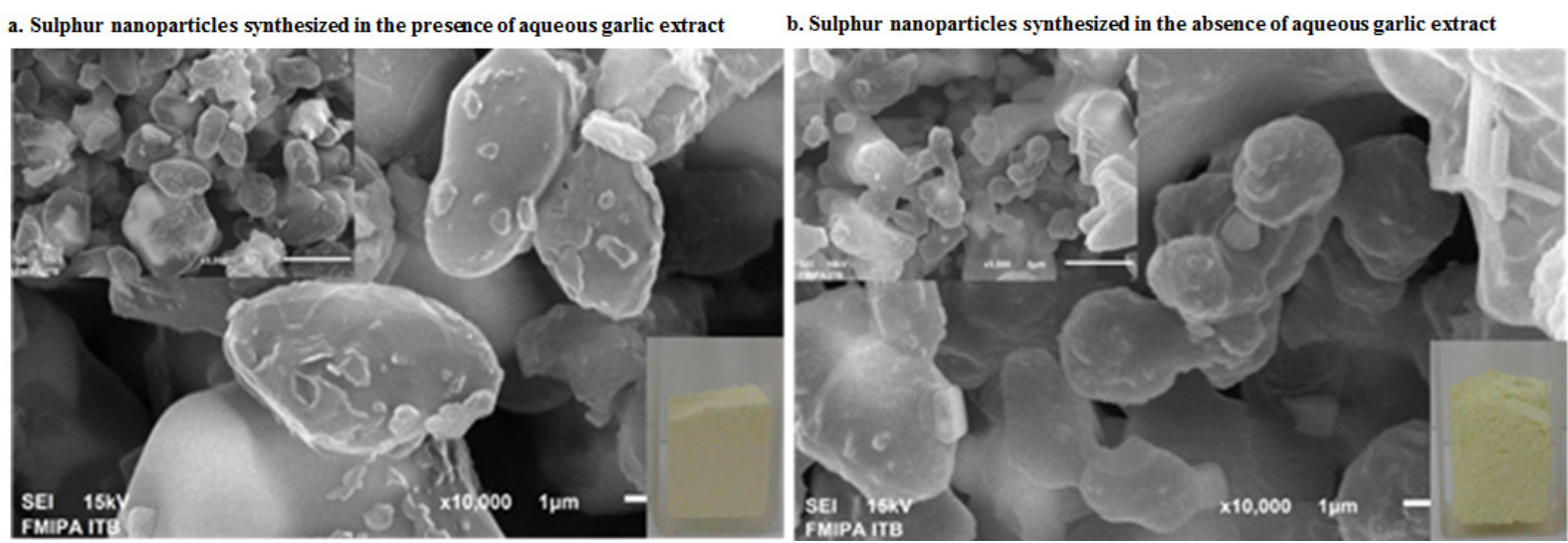

Fig.-4: SEM analysis of sulphur nanoparticles synthesized in the presence of aqueous garlic extract (a) and absence of aqueous garlic extract (b), with the magnification up to 5.000 and $10.000 x$.

a. The activity of sulphur nanoparticles synthesized in the presence of aqueous garlic extract on Candida albicans
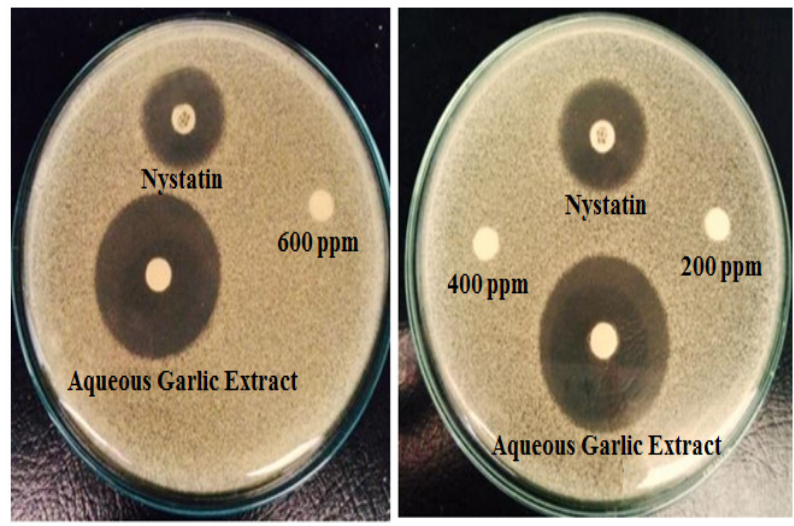

Fig.-5: The activity of sulphur nanoparticles synthesized in the presence (a) and absence (b) of aqueous garlic extract at concentrations of 200, 400, and $600 \mathrm{ppm}$ on clinical isolate of Candida albicans b. The activity of sulphur nanoparticles synthesized in the absence of aqueous garlic extract on Candida albicans

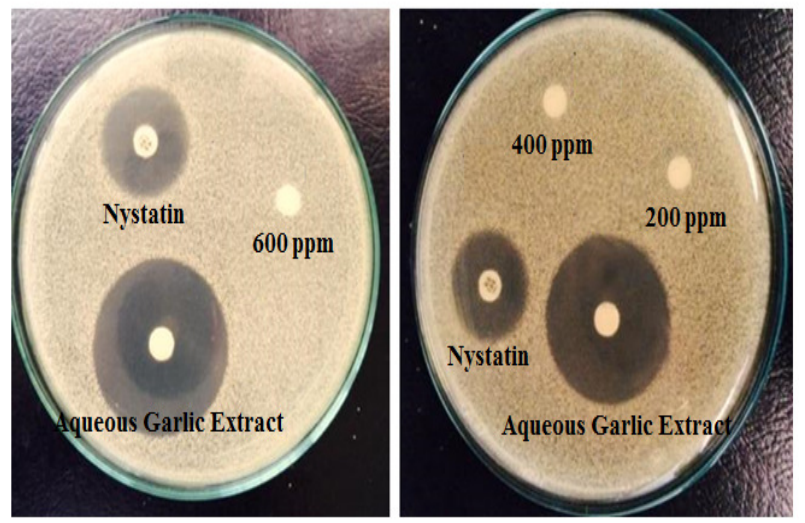

\section{CONCLUSION}

Sulphur nanoparticles have been successfully prepared from sodium thiosulfate pentahydrate in the presence and absence of aqueous garlic extract (Allium sativum). Calculations using the Scherrer equation showed that sulphur nanoparticles synthesized in the presence and absence of aqueous garlic extract were 55.613 and $70.908 \mathrm{~nm}$ respectively. Scanning Electron Microscopy (SEM) results showed that sulphur nanoparticles synthesized in the presence of aqueous garlic extract had clear and smooth spherical shapes. The sulphur nanoparticles synthesized in the presence and absence of aqueous garlic extract showed no effect on Candida albicans at concentrations of 200, 400, and $600 \mathrm{ppm}$. 
RASĀYAN J. Chem.

Vol. 12 | No. 1 |50 - 57| January - March | 2019

\section{ACKNOWLEDGMENT}

We thank the Scientific Research Support Fund of the Ministry of Higher Education and Scientific Research-Indonesia for funding (BCHP: 46/UN11.2/PP/SP3/2016) in the scheme of Fundamental Research.

\section{REFERENCES}

1. G. Pandey, Rasayan J. Chem., 11(3), 942(2018), DOI: 10.31788/RJC.2018.1133031.

2. A. M. Awwad, M. S. Nidá, Amany O., Advanced Material Letters, 6, 432(2015), DOI: 10.5185/amlett.2015.5792.

3. T. Kamakshi, G. Sunita Sundari, Harikrishna Erothu and T. P. Rao, Rasayan J. Chem., 11(3), 1113(2018), DOI: 10.31788/RJC.2018.1134003.

4. K. Khairan, R. Idroes, M. Bahi, K.H. Schaefer, C. Jacob, Jurnal Kedokteran Hewan, 9(1), 78(2015),

5. M. S. Nidá, M. Salem, L. S. Albanna, A. M. Awwad., Environmental Nanotechnology, Monitoring and Management, 6, 83(2016), DOI: 10.1016/j.enmm.2016.06.006.

6. V.V. Makarov, A. J. Love, O. V. Sinitsyna S., S. Makarova, V. Yaminsky, M. E. Taliansk, N. O. Kalinina, 2013, A Review, Acta Naturae, 6(1), 20 (2014)

7. A.T. Harris, R. Bali, J. Nanoparticle Res.,10, 691(2008), DOI: 10.1007/s11051-007-9288-5.

8. A. Manceau, K.L. Nagy, M.A. Marcus, M. Lanson, N. Geoffroy, T. Jacquet, T. Kirpichtchikova, Environ. Sci., Technol., 4(5), 1766(2008), DOI: 10.1021/es072017o.

9. M.N. Owaid, J. Raman, H. Lakshmanan, S. Salem, S. Al-Saeedi, V. Sabaratnam, I.A. Abed, Materials Letters, 153, 186(2015), DOI: 10.1016/j.matlet.2015.04.02.

10. J.K. Patra, Y. Kwon, K.H. Baek, Advanced Powder Technology, 27, 2204(2016), DOI: 10.1016/j.apt.2016.08.005.

11. M. Suleiman, Al-Masri, M. Al-Ali, A. Aref, D. Hussein, A. Iyad Saadeddin, I. Warad, J. Mater. Environ. Sci., 6, 513(2015)

12. M.S. Nidá, L.S. Albanna, A.M. Awwad, Q.M. Ibrahim, A.O. Abdeen, Journal of Agricultural Science, 8, 184(2015), DOI:10.5539/jas.v8n1p188.

13. L. Rastogi, J. Arunachalam, Adv. Mat. Lett., 4(7), 548(2013), DOI: 10.5185/amlett.2012.11456.

14. J.B. Harborne, Springer Nature, Switzerland, 1-32 (1980), DOI: 10.1007/978-94-009-5921-7.

15. S. Shankar, J.W. Rhim, Food Hydrocolloids, 82, 116(2018), DOI: 10.1016/j.foodhyd.2018.03.054.

16. P.V. Kumar, S.M.J. Kala, K. S. Prakash, Rasayan J. Chem., 11(4), 1544(2018), DOI: 10.31788/RJC.2018.1144044.

[RJC-4073/2018] 